\title{
Partial Differential Equations, Control, and Numerics
}

\section{Preface to a Special Issue Dedicated to Enrique Zuazua on the Occasion of his 60th Birthday}

\author{
Jean-Michel Coron ${ }^{1} \cdot$ Sorin Micu ${ }^{2} \cdot$ Hoang Xuan Phu ${ }^{3}$
}

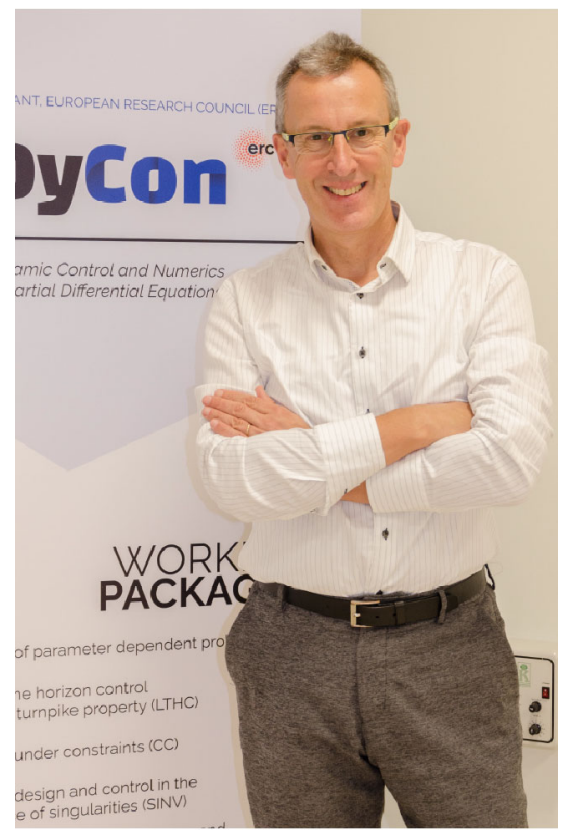

Hoang Xuan Phu

hxphu@math.ac.vn
This special issue is dedicated to Prof. Enrique Zuazua for his 60th birthday. Seventeen original papers are presented, covering many topics to which Enrique has made major contributions. We are grateful to all authors and referees of this volume, for their enthusiastic participation in this adventure.

Enrique Zuazua started his studies in the natal Gipuzkoa-Basque Country-Spain. In 1984 he graduated in Mathematics from the Universidad del País Vasco-Euskal Herriko Unibertsitatea (UPV-EHU) before obtaining a dual $\mathrm{PhD}$ degree from this University in 1987 and the Laboratoire JacquesLouis Lions of the Université Pierre et Marie Curie in 1988. It was during these years when, by completing his doctoral thesis entitled "Comportement global et contrôlabilié exacte pour certains problèmes de type hyperbolique" under the coordination of Prof. Dr. Alain Haraux and by collaborating with Prof. Dr. Jaques-Louis Lions in writing the highly influential monograph "Contrôlabilité Exacte Perturbations et Stabilisation de Systèmes Distribués" (Masson, Paris, 1988), his interest in the theory control and stability has formed. 
During the 1987-1988 academic year, Enrique Zuazua was Associate Professor at UPVEHU, before becoming an Associate Professor in Mathematical Analysis at the Universidad Autónoma de Madrid. In 1990, he won a Professorship in Applied Mathematics at the Universidad Complutense de Madrid where he was Head of the Applied Mathematics Departments at the Faculties of Chemistry and Mathematics. In 2001 he got an Excellence Professorship in Applied Mathematics at Universidad Autónoma de Madrid. During these years he managed to combine in an amazing way the didactic and administrative activities with those of research and doctoral management. A large number of doctoral students from this period have and will keep their whole life alive in memory his dedication, enthusiasm, determination and depth of the transmitted ideas.

From 2008-2012 Enrique Zuazua was the Founding Scientific Director Research of the BCAM - Basque Center for Applied Mathematics, in Bilbao, Basque Country, Spain, created by the Basque Government, with the aim of promoting research into the most computational, applied and multi-disciplinary aspects of Mathematics, where he led the team on "Partial Differential Equations, Numerics and Control" until September 2015 as a Distinguished Ikerbasque Professor of the Basque Foundation for Science Ikerbasque. With great enthusiasm and tireless activity at BCAM, he managed to organize several research teams and to obtain the recognition of the center internationally as one of the leading organizations with a high impact in the scientific community.

From 2016 Enrique Zuazua is the Director of the Chair of Computational Mathematics of Deusto Foundation at University of Deusto, Bilbao (Basque Country, Spain) developing an active research, training and outreach agenda in various aspects of Applied Mathematics.

In 2019 Enrique Zuazua was awarded with a Humboldt Professorship by the Alexander von Humboldt Foundation, which is Germany's best endowed research award, and became the head of the Chair in "Dynamics, Control and Numerics" at the Department of Mathematics at Friedrich-Alexander-Universität Erlangen-Nürnberg (FAU). Recently he joined the newly created Department of Data Science of FAU, that he contributed to launch, together with other colleagues of the Departments of Mathematics, in the context of the HighTech Agenda of the Government of Bavaria.

The domains of expertise of Enrique Zuazua include Control Theory, Numerical Analysis, Partial Differential Equations, Optimal Design, Data Science and Industrial Transfer with an interest in developing and applying methods of Mathematical and Computational Mathematics to model, understand, design and control the dynamics of various phenomena arising in the interface of Mathematics with Engineering, Physics, Biology and Social Sciences. His research work had a high impact on the interplay of these disciplines of Applied Mathematics, having led to new analytical results and to the development of novel numerical methods preserving the asymptotic and control properties of PDEs. These analytical and numerical contributions have been implemented successfully in new computational software, often in a data driven context, applied in a number of industrial projects (optimal shape design in aeronautics and the management of water resources and electrical networks, in particular).

Enrique Zauzua's scientific publishing activity is impressive. An inspection in MathSciNet shows more than 350 articles and more than 7200 citations. He was recognized as a "highly cited researcher" by the ISI Institute (Thompson) in 2004. He develops also an intense agenda of divulgation of science to society, being a tireless supporter and promoter of the idea that mathematics and the mathematicians have an increasing importance in today's world. He once said "We understand Applied Mathematics both as a way of getting into the depth of mathematics and also of interacting with all other scientists and $R \& D$ 
agents", underlining at the same time the intrinsic beauty and the practical relevance of mathematics.

Enrique Zuazua has been serving as an editor of various journals, including Acta Applicandae Mathematicae, Asymptotic Analysis, Collectanea Mathematica, Computational and Applied Mathematics, ESAIM: Control, Optimisation and the Calculus of Variations, Journal de Mathématiques Pures et Appliquées, Journal of Differential Equations, Journal of Optimization Theory and Applications, Mathematical Control and Related Fields (Editor in Chief), Mathematical Models and Methods in Applied Sciences, Mathematics of Control, Signals and Systems, Numerische Mathematik, Systems and Control Letters, and Vietnam Journal of Mathematics.

In recognition of the significant impact of his work, beside the Humboldt Research Award in 2014 and the Humboldt Professorship in 2019, Enrique Zuazua has been awarded with several renowned prizes, such as the SEMA prize for the dissemination in Applied Mathematics in 2001 and 2003, the Euskadi (Basque Country) Prize for Science and Technology in 2006, and the Julio Rey Pastor National Prize for "Mathematics, Information and Communications Technology" in 2007. In 2013, he received the "Research in Paris" award of the Paris City Hall, an Excellence Chair of the CIMI - Centre International de Mathématiques et Informatique de Toulouse. In 2014 he got the Doctor Honoris Causa degree from the Université de Lorraine in France. In 2015 he became a member of Academia Europaea and the first FAU-Ambassador (of the Friedrich Alexander University, ErlangenNürnberg). Recently, he has been awarded as TALENT CIENCIA on the Deia's Talent Awards (Deia Talent Sariak 2021).

Enrique Zuazua has been the principal investigator of two projects financed by the European Research Council - ERC: NUMERIWAVES (2010-2015) dedicated to the study of new analytical and numerical methods in wave propagation and DyCon (2016-2022) on dynamic control and numerics of partial differential equations. Between 2016-2019 he held the chair ACHN - Accueil de Chercheurs de Haut Niveau - Interactions of Control, Partial Differential Equations and Numerics - ICON in partnership with Laboratoire Jacques Louis Lions.

A short description like this cannot do justice to Enrique's activity with students. He attracted many young people, from all over the world, to work with him; he has supervised, according to Mathematics Genealogy Project, at least twenty seven $\mathrm{PhD}$ theses and he has conducted numerous Postdoctoral Fellowships. Many of his students themselves have become well-established mathematicians.

He presented himself somewhere "I'm Enrique, a math passionate". Anyone who had the opportunity to talk to him, listen to a lecture or read one of his articles could easily feel this passion. With his deep understanding of the subject and original insights, he is able to convey his enthusiasm for mathematics to everyone. This is a great gift for which all those who knew him and were in one way or another influenced by him are grateful.

On the occasion of his 60th birthday, we express our deepest respect to Professor Enrique Zuazua and wish him good health and many productive years to come.

Publisher's Note Springer Nature remains neutral with regard to jurisdictional claims in published maps and institutional affiliations. 


\section{Affiliations}

\section{Jean-Michel Coron ${ }^{1} \cdot$ Sorin $\mathrm{Micu}^{2} \cdot$ Hoang Xuan $\mathrm{Phu}^{3}$}

Jean-Michel Coron

coron@ann.jussieu.fr

Sorin Micu

sd_micu@yahoo.com

1 Sorbonne Université, Université Paris-Diderot SPC, CNRS, INRIA, Laboratoire Jacques-Louis Lions, équipe Cage, Paris, France

2 Department of Mathematics, University of Craiova, and "Gheorghe Mihoc-Caius Iacob" Institute of Mathematical Statistics and Applied Mathematics of the Romanian Academy, Bucharest, Romania

3 Institute of Mathematics, Vietnam Academy of Science and Technology, 18 Hoang Quoc Viet Road, Cau Giay District, Hanoi, Vietnam 